\title{
Drama for Language Learning to Adult Learners Through Co-generative Dialogues
}

\author{
Roxana Ahmad Chowdhury \\ United International University, Dhaka, Bangladesh
}

\begin{abstract}
Drama is a motivational, powerful, and feasible technique and tool for language learning. Interactions in the class play an important role. Thus, teachers exploit a number of opportunities to give chance to participants for communication. Writing drama and enacting it can be a good space for generating discussion to develop language skills. Analysis of language interaction in drama focuses on negotiations of language. Co-generative dialogues help participants to focus on the social aspects of life. The interaction and communication to environment play a vital role as it conveys a positive message through performance and fulfills the socio effective requirement. As English Language teaching teachers, we always look for innovative and motivational ideas for language learning and thus, "Drama for language learning through co-generative dialogues" helped me to expand the repertoire of dynamics in the classroom. Drama included co-generative dialogues stage production and performance. It is a powerful and innovative medium for exploring and learning language. It communicated response, moods, and information to the audience. The research explored the effect of drama for language learning through co-generative dialogues, to build cultural awareness, create bondage, meet people, and solve problems.
\end{abstract}

Keywords: Drama, co-generative dialogues, motivation, cultural awareness

\section{Introduction}

Learning and teaching a foreign language requires setting the different contexts for learners to use the learned language as a means of communication. Interactions in the language class through co-generative dialogues play an important role for teachers and learners. Bianchini, Cavazos and Helms (2000) observe that "current efforts to reform education emphasize the need for teachers to transform their educational goals, content, and instructional practices to make curricula more appealing and welcoming to all students, particularly women and ethnic minorities” (as cited in Van, Kate, \& Beers, 2005, p. 147). Writing drama and enacting it are good spaces for developing language skills. Drama evokes higher order thinking, feeling, problem solving, language development, and its usage where students can articulate their knowledge, ideology, and understanding both in oral and written forms (Booth, 1987). "Drama is a unique tool, vital for language development” (Dougill, 1987, p. 114). As writing process of drama involves the personal feelings of the learners, it "transacts" (Hoyt, 1992) different meaning to the different participants to translate their knowledge into motion and verbal interpretation. Podlozny (2000) pointed out that there is a strong and positive relationship between drama skills and communication skills especially, the language outcomes as well as

Roxana Ahmad Chowdhury, Adjunct Lecturer, English Language Institute (ELI), United International University, Dhaka, Bangladesh. 
creativity and self-concept.

The research set out to explore the effect of drama to strengthen co-generative dialogues, build cultural awareness, create bondage, and solve problems. Learners are expected to be able to cogenerate dialogues, interact, establish collaborative learning, communicate and stimulate thinking which would open new vistas, intellectual curiosity, responsibility, and bondage.

In this research, co-generative dialogue illustrates participants' effort to learn languages and use them in different dimensions of daily life considering the race, age, gender, and different social status. The total dialogue starts with the writing stage and the dialogue writing part of the drama starts with individual feelings and ends up with collective efforts through pre-writing reflection, while writing reflection, and at last the rewriting reflection. As in all these three sessions helped learners to generate a lot of discussion. In this regard, it filtered the emotions and feelings of the participants to express differently according to their situation.

When I focused myself to do this research, I was not so familiar with it. I thought and hoped that my research would help me in sorting out some important pieces of the puzzle, such as who was using drama to teach ESL students, why they were doing it, how they were doing it, and to what effect. These constituted main objectives and research questions for my study. Working on this research, my vision widened up and through my research, I found many answers to these questions. I focused discussed and highlighted the benefits by explaining the ideas of the leading educators and linguists who have enriched the field of drama in language education. As they are the initial ones who have identified, documented, and researched reasons for using drama in the classroom. I also discussed the challenges, weakness, and drawbacks of using drama with language students. Consequently, I highlighted how this research assisted me and gave me clues to solve certain puzzles.

The potential benefit of this research on applying drama in the language classroom suggests teaching language to students. To be able to understand more clearly these benefits, I have reviewed the impact of drama that can have on students from macro level as it encourages project based learning to micro level as it helped learning with voice too. The implementation of drama is not a new innovative idea. It is an old concept-a new wine in an old bottle.

\section{The Study's Aims}

1. Explore opportunities to harmonize the classroom environment through co-generative dialogues.

2. Diagnose different types of bondage, social awareness that is created in learners through drama.

3. Examine students' conceptualization of language with co-generative dialogues and drama during language process and production stage.

\section{Literature Review}

"People learn a second language most successfully when the information they are acquiring is perceived as interesting, useful and leading to a desired goal”, Richard and Rogers (2001, pp. 64-65). Hence, it is assumed that drama context for listening and meaningful language production helps learner to use their resources and enhance linguistic abilities. Thus, the participants were divided in different groups to discuss the production of the activities. These discussions produced something new in the class which was useful as they offered teachers and students an opportunity to get involved in co generative dialogues. Co-generative dialogues help us to adapt our perspectives and differences. 
Drama provides an excellent platform for exploring theoretical and practical aspects of the English language (Whiteson, 1996). Drama develops student's communication skills, to create and imagine. They bring real life into the class. Thus, the class becomes interactive and also visual.

This paper explored the opportunity of speaking and writing practice during a drama lesson where students were motivated to write the drama and later to act out by using co generative dialogues. As Chauhan (2004) points out, using drama in teaching English as a foreign language, classes give a context for listening and meaningful language production, forcing the learners to use their language resources and, thus, enhancing their linguistic abilities.

Role-play, a very important and significant role to develop communicative skills and drama in EFL classes, can be used for further development for language skills. Thus, the aspects of role-play helps students to learn to be cooperative to each other, develop empathy for others give value to decision making skills, encourages an exchange of knowledge between students and teacher. It also encourages building leadership, developing team work, teaches to compromise, supports to build authentic listening skills and practice with real life around us.

In addition to the benefits mentioned above, drama also in EFL classes meets the needs of the learners for development. Susan Holden (1981) defines drama as any activity which asks the participant to portray himself in an imaginary situation; or to portray another person in an imaginary situation. The focus of drama is related to the world of "let's pretend". Through drama a person can express himself through verbal expressions and gestures using his imagination and memory. It encourages students to speak, giving them the chance to communicate, even with limited language, using non-verbal communication, such as body movements and facial expressions. Thus, drama reflects our inner self and our imagination as well as our creativity. We are all acting out theatrical performances to present ourselves in regard to how we wish to be seen. When we are in the presence of others, we are to some extent on stage. Whiteson (1996) says that drama is a unique technique because it brings forward the creative thoughts asserting the education of language. It expands learner's expression and creativity.

Hence, we can see that drama is a very useful skill for language learning. Employing drama and dramatic activities makes learning an enjoyable experience, makes the communicative experience more real, and links it with the student's own experience of life, Royka asserts (2002). She states that drama activities can bring life to ESL/EFL classroom and I believe it also.

When drama is introduced in a class, it becomes an enjoyable, fun loving class. The drama is scripted rehearsed and then staged. It is a piece of work which entertains audience. Thus, it improves the reading and writing skills too.

\section{Research Questions}

1. How can drama be harmonized in classroom?

2. How and to what extent is bondage, social awareness created in learners through drama?

3. How and to what extent do co-generative dialogues help during language process and production stage?

\section{Participants}

Students were adult learners from BRAC Education Program, who were Area Managers working in remote places of BRAC. They were enrolled in a course titled Micro Finance Overseas Staff Training. After the completion of the course (Development Professional Course), the managers would be posted in different 
foreign countries to oversee BRAC Programs.

To carry out the research, there were 40 participants and they were divided into two groups. There were 22 male participants and 18 female participants. Their age limit was 35-50 years and most of them had an educational background up to minimum Bachelor's Degree and above. They were from various socio-economic and socio-cultural backgrounds. I had originally selected the participants to enhance their language skills by introducing drama as a tool which later led to this context for research. From the conversation and interview with them, it became evident that they were fluent in Bangla but not so much in English. Initially, they were shy and there was the fear of losing face value but soon they were at ease.

\section{Methodology}

A mixed method approach was applied for collecting the necessary data. A balance of qualitative, quantitative, and ethnographic research was applied to get the necessary information. It was easy to interview the participants and accumulate data as the participants were under the service residential training; it was convenient to interview and accumulate data through:

- Recording dialogues during their interaction and later manuscript to analyze the proficiency of the language participants.

- Interview with the participants and teachers during formative assessment period.

- Conducting a Focus Group Discussion.

- Comparing their drama scripts with previous writing samples to check the usage of everyday English.

- Questionnaire.

\section{Research and Development}

Research and development have no special type of data source. Data has been collected by observation, interview-questionnaire and focus group which are some of the notable characteristics of qualitative approach. By using bar graph, it gives the paper, to some extent, a shape of quantitative approach.

The research helped me to determine that drama can be incorporated through co-generative dialogues to assist learners. Drama classes helped students to create confidence, which gave fluency and helped learners to reach potentiality. It projected real life. They used tools to generate unrehearsed language from the rehearsed language.

\section{Research Instruments}

Questionnaires were distributed to the learners and as a teacher and I compiled it for data collection. Interviews were taken of the students. The recorded dialogues during the interaction were scripted which helped to analyze the proficiency of the language participants.

\section{Questionnaire}

To collect the data a questionnaire was designed. The questionnaire consisted of structured questions. It was designed to elicit the students' motivation and attitude towards the use of English language. The reasons why the students frequently switch codes between Bangla and English were measured following another 4-point scale ranging from agreement to disagreement. It was done intentionally to elicit the ratio of code switching among the students. 


\section{Interview}

To conduct the research, I took interview of students to get some in-depth data. It was actually one type group interview and the groups were comprised of about four to six members. I jotted down the important issues very tactfully and carefully without making them embarrassed. I used a pen and paper for noting down the important answers and also recorded their views.

\section{Observation}

I availed myself of the opportunity to observe very often how the students talked to each other using co generative dialogues and their verbal repertoire. I was very careful to listen to how they borrowed and mixed English words and phrases in Bangla sentences.

The research helped to determine that drama can be incorporated through co-generative dialogues to assist learners to improve their skills on the target language. It created a field where the stakeholders collectively shared their classroom experience with the intention of improving the learning of the students.

\section{Findings and Analysis}

I observed the participants for three to four weeks and saw the difficulties the participants faced and conceptualized new lesson and new language ideas. The learners were always motivated to make use of their knowledge. I tried to help them when they faced any negative motivational factors and assisted them with knowledge that would help them to build their own learning. I supported their ideas and tried to get them out of their shell as they were initially shy.

This research, thus, gave opportunities to connect and reflect on how drama can be used as a tool for language improvement challenging the temporary learning difficulties through co-generative dialogues by creating social awareness and created bondage to bring harmony. Drama classes helped students to create confidence, which gave fluency and helped learners to reach potentiality. Speaking, reading, writing, and listening skills were improved. The physical gesture and facial expressions naturally and intuitively conveyed and responded. Thus, it is crafted that drama can be used to communicate effectively for language learning.

The student sat in groups and worked on the drama preparing their script. Most of the students could explain quite well while there were others who talked vaguely. Once the script was written, the characters were chosen. Each participant had to memorize their dialogues and they had to rehearse and get ready to perform the drama.

Thus, from the students' discussion, we can see that they had created a harmonious environment. The social issues were reflected very prominently through the script. Speaking and thinking were closely linked and co-constituted. The students sometimes used Bengali but then again they rectified themselves.

The students collected different costumes and got ups for their specific roles. When they got into their costumes as well as their character, the maximum punch was derived. Students made good preparation and time reflection with great care and performed their roles. But, then the classroom performance can be a stage performance but it does not lead to public performance. Thus, we see through co-generative dialogues the students created harmonious atmosphere and prepared a script for a drama.

From the questionnaire provided, we found that out of 40, 36 participants agreed strongly to state that there was an opportunity to use the everyday language. On the other hand, four participants agreed on the statement. 


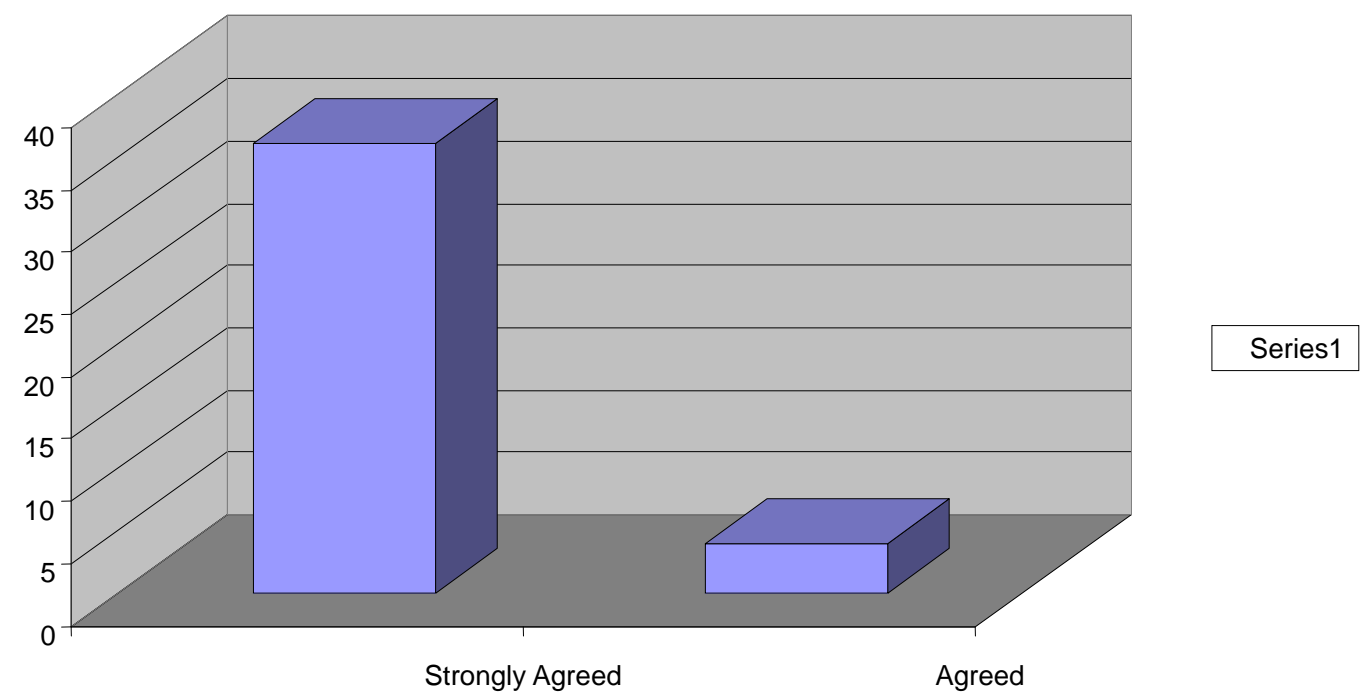

Figure 1. The response of the participants.

It is important to note here that none of the participants feel any inhibition in terms of everyday language usages and it was reflected in the other opinion when they were asked how confident they were in using languages. From the interview questionnaire, it was found that $70 \%$ of the participants feel strongly that they were confident to use the language. On the other hand, $25 \%$ of them feel just confident and $5 \%$ were neutral to state whether drama could boost their confidence to speak publicly.

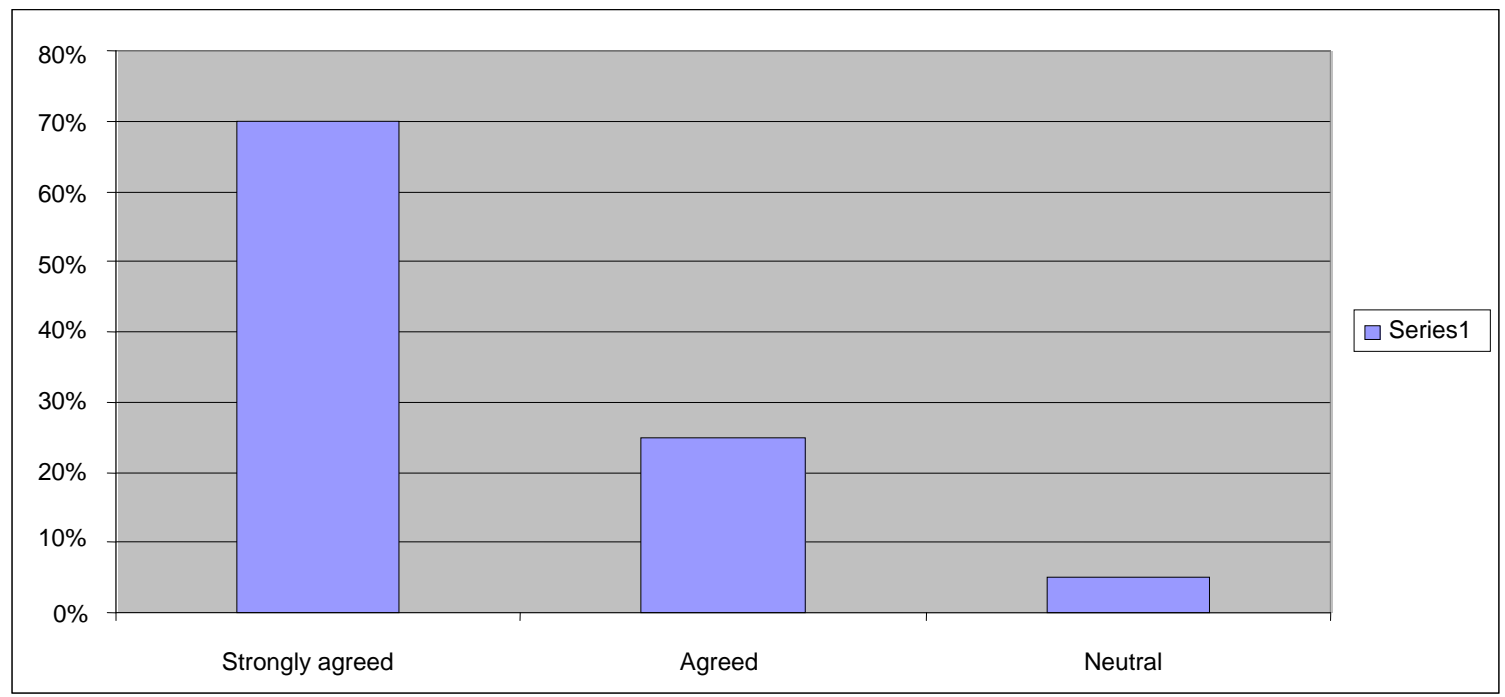

Figure 2. How the activity helped the Participants.

The brunt of the findings goes with the open question where the participants had the opportunities to reflect how this activity helped them in the professional and personal life. 


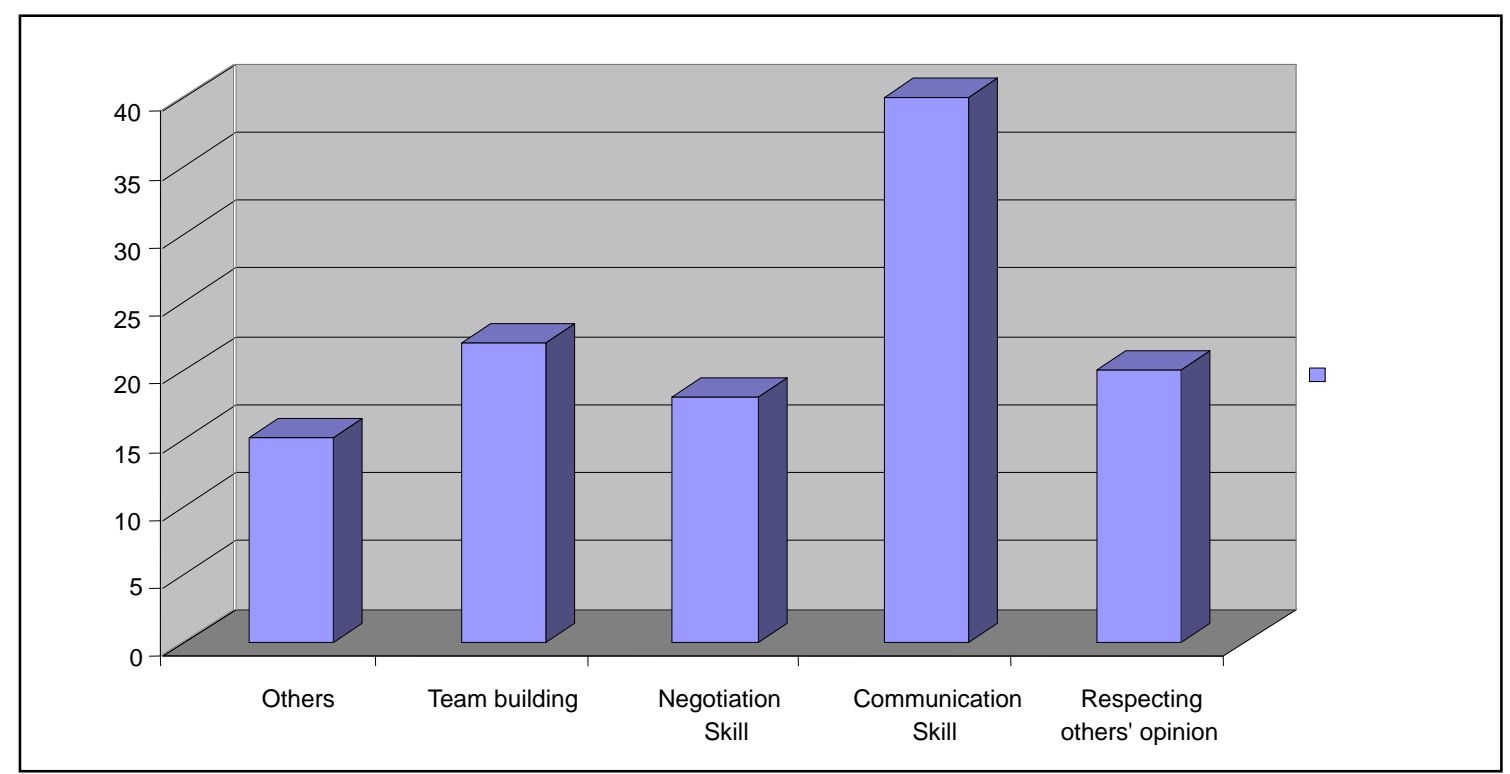

Figure 3. The overall responses of the participants.

Needless to mention, all the participants agreed that this type of activity helped them a lot to improve their communication skill. The other variables like team building, developing negotiation skill, respecting others' opinion, emotional attachment, and motivational factors also helped them.

\section{Recommendation and Conclusion}

From the analysis, we see that drama expresses realities and helps to build co-generative dialogues. It creates characters, plots, gives pragmatic intent and creativity. It helps students to use resources and enhance linguistic abilities. Analysis of language interaction focuses on negotiations of language. Hence, L1 learners managed to enhance their language skills through co-generative dialogues.

This research, thus gave me opportunities to connect and reflect on how drama can be used as a tool for language improvement challenging the temporary learning difficulties through co-generative dialogues by creating social awareness and also at the same time harmonize bondage.

\section{References}

Booth, D. (1987). Drama words. Toronto. Ont: Language Study Centre, University of Toronto.

Chauhan, V. (October 2004). TESL Journal, X(10). Retrieved from http://iteslj.org/ http://iteslj.org/Techniques/Chauhan-Drama.html.o Retrieved on December 15, 2012, from https://www.facebook.com/Sykpe School of English ref=hl

Doughill, J. (1987). Drama activities for language learning. London: Macmillan Education Limited.

Holden, S. (1981). Drama in language teaching. Essex: Longman Imber and Toffler (2000). Dictionary of Marketing Terms (3rd ed.). New York: Barron's Educational Series. Retrieved on September 15, 2012, from http://www.answers.com/library/Marketing+Dictionary-letter-1F-first-101\#ixzz27k3aXWDm

Hoyt, L. (1992). Many ways of knowing: Using drama, oral interactions, and the visual arts to enhance reading comprehension. The Reading Teacher, 45(8), 580-584.

Podlozny, A. (2000). Strengthening verbal skills through the use of classroom drama. Journal of Aesthetic Education, 34(3/4), 239-275.

Richards, J. C., \& Rodgers, T. S. (2001). Approaches and methods in language teaching (2a. ed.). Cambridge: Cambridge University Press. 
Royka, J. (June 2002). Overing the fear of using drama in English language teaching. The Internet TESL Journal, 8(6). Retrieved on November 13, 2012, from http://iteslj.org/Articles/Royka-Drama.html

Van, L., Kate, S., \& Beers, J. (2005). The role of co-generative dialogue in learning to teach and transforming learning environment. In K. Tobin, R. Elmesky, and G. Seiler (Eds.), Improving urban science education: New roles for teachers, students, and researchers. Rowman and Littlefield Publishers.

Whiteson, V. (1996). New ways of using drama and literature in language teaching. Alexandria, VA.: TESOL. 